\title{
Volatility in Construction: Different Dimensions and Types of Changes
}

Zhuoyuan Wang, Benson T.H. Lim, and Imriyas Kamardeen

(University of New South Wales, Australia)

\begin{abstract}
Effective change management has been touted as the next strategic weapon for competitiveness. The aim of this paper is to investigate the dimensionality of changes in construction. Under this aim, the specific objectives are to: define and classify the types of changes; and operationalize the types of changes. The literature review reveals that changes in construction could categorise along five dimensions: time; need; effect; process; and environment. Each dimension comprises at least two different types of changes. The identified dimensions and types of changes will be tested in the next stage of a research project, and thereafter the empirical findings will attempt to provide industry practitioners indepth insights into different constituents of change that could affect their business operation.
\end{abstract}

Keyword: Construction Firms, Changes, Competitiveness

\section{Introduction}

Environmental changes in construction are growing at an increasingly rapid pace and are offering consistently greater strategic opportunities with time, while posing significant threats. Change management is thus one of the key approaches for firms to remain viable in a changing business environment (Price and Chahal, 2006; Lewis, 1994). However, managing changes effectively is not an easy task; as changes in construction may vary in types, scale and quantity. Different dimensions and types of changes may bring about varied influences on firms, and require the firms to adopt and configure different responsive strategies in order to remain viable. It is therefore important for firms to appreciate the dimensions and types of changes in construction.

The aim of this paper is to investigate the dimensionality of changes in construction. Under this aim, the specific objectives are to: define and classify the types of changes; and operationalize the types of changes. Ascertaining and operationalizing the types of changes are important because it provides a framework for researchers and practitioners towards appreciating different constituents of changes that could affect business performance, and evaluating the market volatility. The identified dimensions and types of changes will be tested in the next stage of a research project.

\section{Definition of Changes}

Ven and Poole (1995) stated that change is an empirical observation in an organizational entity of adaptions in shape, quality or state over time. Boeker (1997) expanded on the definitions of Barr et al. (1992) and Child and Smith (1987), defining change as an adjustment to the environment or an promotion in performance). Change also has been defined as the adoption of a thought or behaviour (a system, process, policy, program, or service etc.) that is new to the adopting organization (Damanpour and Evan, 1984; Daft, 1982; Aiken and Hage, 1971).

Change represents something that people have not expected. Kotter and Cohen (2002) identified change as a reality of people need to deal with new technologies, mergers and acquisitions, restructurings, new strategies, cultural transformation, globalization, and ebusiness on organizational level. Bridges (2010) defined change as the new site, the new boss, the new team roles, the new policy and other things which are situational, comparing 
to 'transition' which is a psychological process. In Stagg and Robbins (2008)'s opinion, change in organizations is the factor which brings planning variations, environmental uncertainty, complicate decision-making process, and so on. While Damanpour (1988) defined change on organizational level as either responding to changes in its environment or as a 'pre-emptive' action. According to Raftery and Loosemore (2006), changes could be risks or opportunities to construction industry. In this paper, changes are defined as a situation happened in construction industry which offering consistently greater strategic opportunities with time, while posing significant threats.

\section{Methods}

In this research, a literature search was conducted to examine those peer-reviewed articles on changes in business environments and change management in project and organisational contexts. Of these, articles were searched electronically in those databases relating to architectural, engineering, construction and business management (e.g. Science Direct, Emerald, Ecospecifier, Jstor and Sage Journals). Several keywords were used to facilitate literature research. Irrelevant topics such as climate change had been excluded.

The purposes of searching and reviewing literature are: (1) to investigate whether change is an integrative multi-dimensional concept; and (2) what the key dimensions of change are.

\section{Dimensionality of Change}

Management literature suggested that change is an integrative multi-dimensional concept rather an independent variable that can be defined and measured in isolation (Johnson and Scholes, 1997; Pritchett and Pound, 1995). However, it appears that there is a shortage of widely accepted and robust capacity to measure change. It follows that the need to develop a generalized set of valid measures for empirical testing of hypothesis about the concept of change.

The review of literature (e.g. Motawa et al. 2007, Johnson and Scholes 1997, and Pritchett and Pound 1995) revealed that the identified dimensions and types of changes could be classified and streamlined into five categories. . Dimensions and types of changes are discussed below.

\section{Time dimension}

\section{Anticipated and emergent changes}

Senaratne and Sexton (2011) reported that anticipated changes are planned forward and happen as intended, and, emergent changes emanate spontaneously and are not originally anticipated or intended. The former allows organizations to make more preparation, while the latter should be urgent enough to push the organizations to implement change management no matter whether they are ready or not.

\section{Proactive, reactive and crisis changes}

'Proactive', 'reactive', and 'crisis' are the most popular vocabularies to describe changes nowadays. van der Wiele et al. (2001) defined proactive change as the ways that managers use their resources actively to develop society independent of a direct benefit to the firms. Society for Human Resource (2005) believed that reactive change is that kind of change that customers, competitors, shareholders, employees, and other critical stakeholders lease signals to organization suggesting that there are needs to change. Price and Chahal (2006) described crisis change as one kind of change which is driven by the fear of failure and the external environmental factors. 


\section{Pre-fixity and post-fixity changes}

Senaratne and Sexton (2011) defined pre-fixity changes as the changes that happen in the design development stage, and post-fixity changes are those that occur after the design development stage. This classification is based on one specific stage of the construction project lifecycle. It is have higher occurrence on project change management perspective than on organizational perspective.

\section{Need dimension}

\section{Elective and required changes}

Ibbs et al. (2001)defined required change as a variation needed to bring the project design in order to comply with a building code, and suggested that it is imperative and should be reviewed and processed differently than an elective change. They added that elective change gives management an option to optimize the original project goals, budget, or schedule.

\section{Discretionary and non-discretionary changes}

Egan (2007) described non-discretionary change as dictated change, and, of discretionary change is central to mediocrity.

\section{Effect dimension}

The effect perspective is based on the results of changes. Everyone seemed to be terrified of change, actually, not all the changes lead to a negative result. For example, economic change could bring some financial crisis for the construction industry, but the price reduction of construction materials, equipment and labours are undeniable fact. Based on this, changes could be divided into beneficial ones, neutral ones and disruptive changes. These classifications should be considered in the specific situation, the same kinds of change could be beneficial for one company but disruptive for another.

\section{Process dimension}

Incremental, punctuated, and continuous changes

The continuous model stays at the highest level, which make organizations to develop the capacity to change itself continuously in a radical manner in order to survive. The punctuated model follows it, which has the primary patterns of activities that are punctuated by relatively short bursts of fundamental change. Incremental model treats changes as being a procedure whereby individual parts of an organization deal incrementally and separately with one problem and one target at a time (Burnes, 1992).

\section{Developmental, transitional, transformational changes}

Development changes which doing more of, or better than the current situation. As for transitional change, it dismantles existing ways and formulating new situations and strategies. Transformational changes involve implementing an evolutionary new circumstance, requiring major and continued shifts in organizational strategy and vision(Pritchett and Pound, 1995).

\section{Environmental dimension}

Changes could be classified in terms of environment, i.e. internal and external. Internal environmental changes happen due to these elements in the internal of organizations. According to Price and Chahal (2006), the updating of technologies is one example of internal environmental changes. Those external environmental changes come from the external side of organizations, which is more complicated than the internal environment. 
Stagg and Robbins (2008) defined the external environment as the forces and institutions outside organizations that potentially have influence on their performance. They also divided the external environment into two parts: the specific environment and the general environment. The specific environment has four important components: suppliers, competitors, public pressure groups, and customers. While global, economic, political/ legal, sociocultural, demographics, and technological are included in the general environment.

Table 1 shows the re-classification of different changes dimensions and types. The differentiating of change in time dimension is based on the time that change had been detected. The change is being detected before or after the time it begins to affect organizations is the key indicator of this dimension. Changes such as proactive change, anticipated change, pre-fixity change are all those changes could be foreseen before it happens, while emergent change, reactive change, crisis change and post-fixity change require organizations to be flexible and vigilant in order to mitigate the impact of those disruptive events on their businesses. Kajewski et al. (2001) recognised the definitions 'proactive change' and 'anticipated change' are overlapped, so they replaced 'proactive change' to 'anticipatory change' when they were researching the cost and difficulty trends of on different changes on time dimension. As for these overlaps, changes on time dimension could be divided into three types: proactive change, reactive change, and crisis change.

Table 1: Re-categorization of change dimensions and types

\begin{tabular}{c|c|c|c|c}
\hline \multirow{2}{*}{ Dimension } & \multicolumn{3}{|c}{ Different types of change } \\
\hline \multirow{2}{*}{ Nime } & anticipated & \multicolumn{2}{c}{ emergent } \\
\cline { 2 - 4 } & proactive & reactive & crisis \\
\cline { 2 - 4 } & pre-fixity & \multicolumn{2}{c}{ post-fixity } \\
\hline \multirow{2}{*}{ Effect } & elective & \multicolumn{2}{|c}{ required } \\
\cline { 2 - 4 } & discretionary & & \multicolumn{2}{c}{ non-discretionary } \\
\hline \multirow{2}{*}{ Process } & beneficial & neutral & disruptive \\
\cline { 2 - 4 } & incremental & punctuated & continuity \\
\hline \multirow{2}{*}{ Environmental } & developmental & transitional & transformational \\
\hline
\end{tabular}

According to Sun et al. (2005), the necessity of the change is the basis of need perspective of change. An elective change is a change that management can choose whether to implement or not, while required change leave the management no choice but to make that change. The words 'discretionary' and 'non-discretionary' in the construction industry is originally used to describe if a project has a choice in implementing or not. It is almost the same meaning with elective or required. So, elective change and required change could answer the represent all kinds of changes in this dimension.

The influence of changes towards organizations is the key criteria in evaluating the effect dimension of change. For organizations, they should launch or utilize beneficial change to increase their competitiveness in the environment, by trying their best to transfer the neutral change into beneficial change, and avoiding or minimizing the negative impacts from disruptive change.

Wang, Z., Lim, B.T.H., and Kamardeen, I. (2012) 'Volatility in construction: Different dimensions and types of changes', Australasian Journal of Construction Economics and Building, Conference Series, 1 (2) 13-20 
There are six types of changes from two different groups in process dimension. Both groups of changes represent different degrees of changes. Transformational change and continuity change stand for those changes having the highest degree of outcomes - both will achieve radical and evolutionary future states for organizations- while incremental change and developmental change are much like upgrading improvements for organizations. To a certain extent, the two groups are overlapped, but for incremental, punctuated, and continuity changes, they contain one more levels of meaning that whether the change affects the organization in a persistent manner or not, the continuity change having the highest persistent process among these three types of changes. 'Incremental, punctuated, and continuity' are more informative and accurate to describe changes in the process dimension.

According to Stagg and Robbins (2008), the internal and external environments of organizations cannot be evaluated in isolation. The two kinds of environments are interlinked. An external environmental factor such as an upgrade in labour regulation, for instance, will definitely cause an unpredictable turmoil in organizational structure in the internal environment. But the pattern, process, and strategy of managing a change on organizational structure will never be the same as those on managing a change on regulations and laws. Thus, figuring out which part of environment that the change comes from is not only useful in managing it but necessary.

\section{The Key Features and Connections between Different Types of Changes}

Change management is a complicated process of managing an organization, the identification of changes should be delicate, as identifying change is the first step of managing it. It serves as a foundation of the management process, so any mistake could steer the entire change management process to an unknown direction and in turn have a negative consequence on the organization's operation, hence performance.

As listed in the third part of this paper, there are many types of changes, and these attributes of these changes are not stable all the time. It can switch from one kind of change to another one which could be an extreme opposite of the previous one. Identifying the types of changes is not as easy as it looks like. The key features of these dimensions and the differences and connections among these dimensions need to be understood by change management implementers in order to discriminate change types accurately.

From the time dimension, according to Society for Human Resource (2005), there are both advantages and disadvantages relying in each of the timing choices. Timely and carefullyplanned implementation is not easy. Lacking the sense of urgency could deter the change management process (i.e. anticipated and proactive change management). However, if the situation is of utmost urgency, management could face many unexpected obstacles in developing systematic plans for effective implementation (i.e. emergent and crisis change management).

The need perspective is based on the demands of organizations. For instance, the required nature of changes is of higher priority than the elective ones in organizational schedule; as the former could exert negative impact on the organisation's business performance if not managed properly and timely. As for the elective nature of changes, they are of less urgency; organizations have more time to develop systematic plans for implementation. To a certain extent, required changes are of similar nature to those of reactive, emergent andnondiscretionary changes on time perspective, while elective changes are similar to those of proactive changes.

Senior and Fleming (2006) described incremental changes as smooth changes that slow, systematic and evolutionary, which share the same feature of proactive changes on the time perspective. Continuous change requires organizations to adopt a proactive attitude to, develop thorough implementation plans. According to Redfern and Christian (2003),

Wang, Z., Lim, B.T.H., and Kamardeen, I. (2012) 'Volatility in construction: Different dimensions and types of changes', Australasian Journal of Construction Economics and Building, Conference Series, 1 (2) 13-20 
developmental change can be either planned or emergent and it proves incrementally over time, while transitional change tends to be episodic and radical. Transformational changes stands at a higher level, signifying the future uncertain state of changes, which cannot be anticipated.

Various changes could have different impacts on organizations, despite the ways that organizations response to them. The attributes of respective changes do have considerable effects on organizations. Figure 1 shows the hypothetical model of organisational change management. In this research, organizations should be seen as complex adaptive and open systems, which inevitably interact with internal and external environmental forces - just like an elastic ball, and the changes are the pressures to this ball. The ways the pressures forcing the ball could explain the processes changes affecting the organizations.

It can be seen from Figure 1 that three dimensions could be set for the sphere: horizon, vertical and the third dimension representing the time dimension, need dimension and effect dimension. The magnitude of the force stands for the process perspective and the location and direction of the force (inside or outside the sphere) could denote the source triggering changes (i.e. from internal or external environment).

For the horizontal axis, which stands for the time perspective, the strength of this direction shows the level of preparedness for the changes. When the strength intensifies, it means that the changes are not of utmost urgency nature, and that organizations have more time to plan and prepare for the relevant changes. The more the organizations are ready for the changes, the more positive effects could effect on the organizations.

The vertical axis presents as the degree of necessity. When the strength intensifies, it signifies that the changes become essential and required for organisations to remain viable.

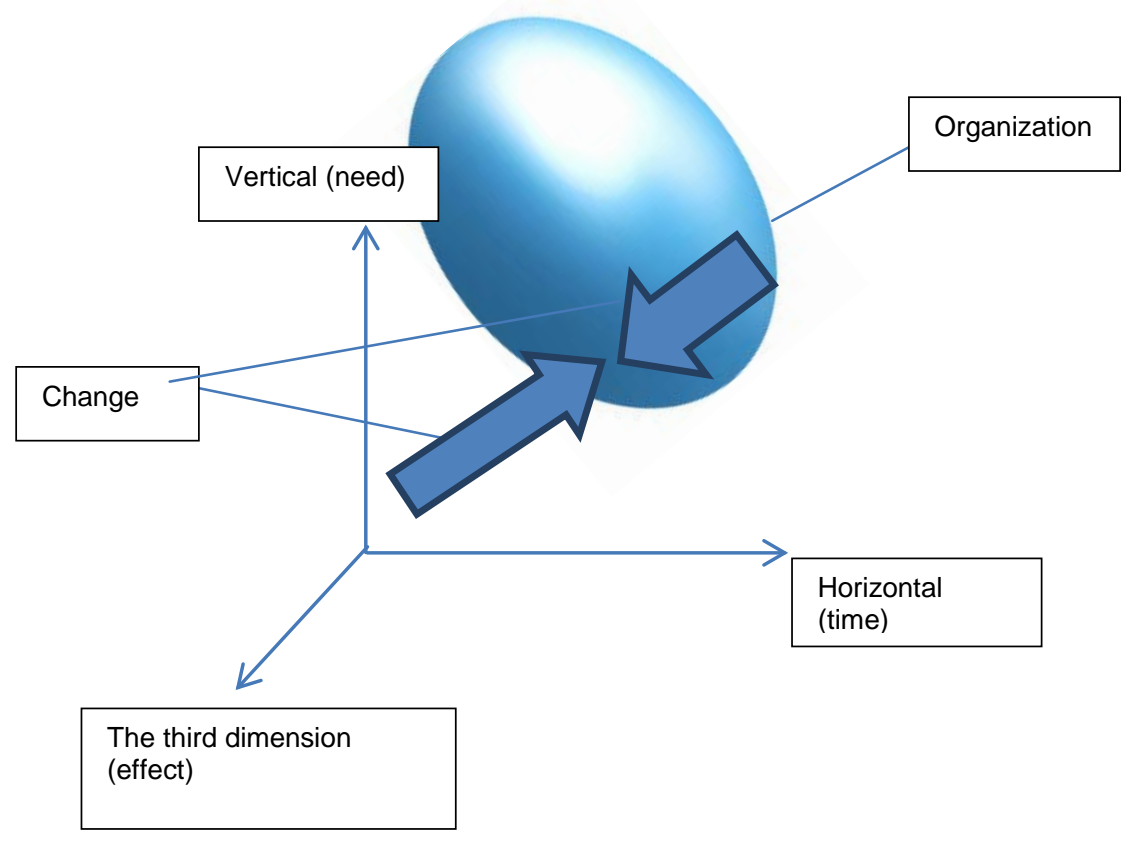

Figure 1: The different dimensions of changes

The effect perspective of changes is demonstrated in the third dimension of the system. Beneficial change stands for the positive position on this direction, while negative position is used for disruptive change. As Raftery and Loosemore (2006) stated, the effect of a change 
will not remain static, risks and opportunities brought by the change are always stay together. A disruptive change could be beneficial to an organization if an effective management strategy is implemented.

The strength of the forces represents the process perspective of changes. Developmental change has the weakest impact and the highest frequency on the organization, while transformational change has radical influence on it. As for transitional change, it has moderate impact on the organizations. That is because different levels of changes will consume different amount of resources of organizations, and investment for controlling changes and offset the influences of changes could be varied.

The position of changes, as shown in Figure 1, mirror the real-life scenario, it could force organizations to adapt the internal and external changes. For changes from the different environments, even if the other attributes such as time attributes, need attributes, process attributes are all the same, different strategies are required for effective management.

\section{Conclusion}

This study investigated the dimensionality of changes in construction. Five dimensions of changes were identified: time, need, effect, environmental and process. Time dimension is related to proactive changes, reactive changes, and crisis changes. The need dimension could be operationalized into elective change and required change, while effect dimension is related to beneficial change, neutral change and disruptive change. As for process dimension, it is dealing with changes of incremental, punctuated, and continuity nature. These dimensions attempt to provide these practitioners a tool to analyse the attributes of changes, evaluate the consequence, and then configure and implement corresponding responsive strategies.

\section{References}

Aiken, M. \& Hage, J. 1971. The Organic Organization And Innovation. Sociology, January, 63-82.

Barr, P., Stimpert, J. L. \& Huff, A. 1992. Cognitive Change, Strategic Action, And Organizational Renewal. Strategic Management Journal, 13, 15-36.

Boeker, W. 1997. Strategic Change: The Influence Of Managerial Characteristics And Organizational Growth. The Academy Of Management Journal, 40, 152-170.

Bridges, P. W. 2010. Managing Transitions: Making The Most Of Change, Readhowyouwant.Com, Limited.

Burnes, B. 1992. Managing Change, Pitman.

Child, J. \& Smith, C. 1987. The Context And Process Of Organizational Transformation - Cadbury Limited In Its Sector. Journal Of Management Studies, 24, 565-593.

Daft, R. L. 1982. Bureaucratic Versus Nonbureaucratic Structure And The Process Of Innovationand Change. Research In The Sociology Of Organizations, I, 129-166.

Damanpour, F. 1988. Innovation Type, Radicalness, And The Adoption Process. Communication Research, October, 545-567.

Damanpour, F. \& Evan, W. M. 1984. Organizational Innovation And Performance: The Problem Of "Organizational Lag". Administrative Science Quarterly, 29, 392-409.

Egan, G. 2007. The Skilled Helper: A Problem-Management And Opportunity-Development Approach To Helping, Thomson Brooks/Cole.

Ibbs, C. W., Wong, C. K. \& Kwak, Y. H. 2001. Project Change Management System. Journal Of Management In Engineering, 17, 159-165.

Johnson, G. \& Scholes, K. 1997. Exploring Corporate Strategy, Prentice Hall.

Wang, Z., Lim, B.T.H., and Kamardeen, I. (2012) 'Volatility in construction: Different dimensions and types of changes', Australasian Journal of Construction Economics and Building, Conference Series, 1 (2) 13-20 
Kajewski, S., Tilley, P., Crawford, J., Remmers, T., Chen, S.-E., Lenard, D., Brewer, G., Gameson, R., Kolomy, R., Martins, R., Sher, W., Weippert, A., Well, G. C. \& Haug, M. 2001. Industry Culture: A Need For Change. Program C : Delivery Management Of Built Assets. Brisbane: Crc For Construction Innovation.

Kotter, J. P. \& Cohen, D. S. 2002. The Heart Of Change: Real Life Stories Of How People Change Their Organizations, Boston, Harvard Business School.

Lewis, P. 1994. The Successful Management Of Redundancy, Blackwell Publishers.

Motawa, I. A., Anumba, C. J., Lee, S. \& Peña-Mora, F. 2007. An Integrated System For Change Management In Construction. Automation In Construction, 16, 368-377.

Price, A. D. F. \& Chahal, K. 2006. A Strategic Framework For Change Management. Construction Management And Economics, 24, 237-251.

Pritchett, P. \& Pound, R. 1995. A Survival Guide To The Stress Of Organizational Change, Pritchett \& Associates.

Raftery, J. \& Loosemore, M. 2006. Risk Management In Projects, Taylor \& Francis.

Redfern, S. \& Christian, S. 2003. Achieving Change In Health Care Practice. Journal Of Evaluation In Clinical Practice, 9, 225-238.

Senaratne, S. \& Sexton, M. 2011. Managing Change In Construction Projects: A Knowledge-Based Approach, Wiley.

Senior, B. \& Fleming, J. 2006. Organizational Change, Harlow, Prentice Hall.

Society For Human Resource, M. 2005. The Essentials Of Managing Change And Transition, Boston, Mass., Harvard Business School Press.

Stagg, R. B. \& Robbins, S. P. 2008. Management, Pearson Education Australia.

Sun, M., Sexton, M., Aouad, G., Fleming, A., Senaratne, S., Anumba, C., Chung, P., El-Hamalawi, A., Motawa, I. \& Yeoh, M. L. 2005. Managing Changes In Construction Projects. Engineering And Physical Sciences Research Council.

Van Der Wiele, T., Kok, P., Mckenna, R. \& Brown, A. 2001. A Corporate Social Responsibility Audit Within A Quality Management Framework. Journal Of Business Ethics, 31, 285-297.

Ven, A. H. V. D. \& Poole, M. S. 1995. Explaining Development And Change In Organizations. The Academy Of Management Review, 20, 510-540. 